\title{
“DESIGNER BABIES": ASPECTOS BIOÉTICOS DA SELEÇÃO EMBRIONÁRIA NA REPRODUÇÃO HUMANA ASSISTIDA.
}

\section{${ }^{1}$ Ana Letícia Valladão Giansante ${ }^{2}$ Sérgio Nojiri}

\section{RESUMO}

O artigo consiste no estudo das técnicas de reprodução humana e engenharia genética, analisando aspectos éticos e possíveis repercussões jurídicas. Dentre as polêmicas, destaca-se a possibilidade de seleção embrionária visando à escolha de características estéticas - "designer babies" -, bem como a seleção com finalidade terapêutica, além dos critérios para a diferenciação dessas hipóteses. Nesse cenário, ressalta-se a importância da Bioética e do Biodireito frente aos problemas que emergem e à possibilidade de ressignificações que alguns direitos podem assumir perante a sociedade contemporânea que usufrui, cada vez mais, de técnicas que podem dar uma nova face às futuras gerações.

Palavra-chave: Reprodução Humana Assistida; Engenharia Genética; Eugenia; Seleção Embrionária; Direitos Fundamentais.

\section{"DESIGNER BABIES": BIOETHICS ASPECTS OF EMBRYONIC SELECTION IN ASSISTED HUMAN REPRODUCTION.}

\begin{abstract}
The article consists of the study of the techniques of human reproduction and genetic engineering, analyzing ethical aspects and possible legal repercussions. Among the controversies, we highlight the possibility of embryonic selection aiming at the choice of aesthetic characteristics - designer babies - as well for therapeutic purposes, besides the criteria for the differentiation of these hypotheses. In this scenario, the importance of Bioethics is highlighted in the face of the problems that arise and the possibility of resignificances that some rights may assume before contemporary society that increasingly enjoys techniques that can give a new face to future generations.
\end{abstract}

Key words: Assisted Human Reproduction; Genetic Engineering; Eugenics; Embryonic Selection; Fundamental Rights.

\section{INTRODUÇÃO}

\footnotetext{
${ }^{1}$ Mestranda em Desenvolvimento no Estado Democrático de Direito pela Faculdade de Direito de Ribeirão Preto da Universidade de São Paulo - FDRP/USP, São Paulo (Brasil). E-mail: ana.giansante@usp.br

${ }^{2}$ Doutor em Direito pela Pontifícia Universidade Católica - PUC, São Paulo (Brasil). Professor de Graduação e Pós-Graduação pela Faculdade de Direito de Ribeirão Preto da Universidade de São Paulo FDRP/USP, São Paulo (Brasil).E-mail: nojiri@usp.br
} 
O presente artigo tem como finalidade apresentar, sinteticamente, a evolução da biomedicina no que concerne às técnicas e possibilidades de reprodução humana assistida, analisando os aspectos éticos e morais com possíveis implicações relevantes no âmbito jurídico.

Dentre as polêmicas, destaca-se a possibilidade de seleção embrionária visando à escolha do sexo, cor dos olhos, dos cabelos, dentre outras características estéticas, que dariam espaço aos denominados "designer babies", e se os mesmos limites são impostos quando o uso de tais procedimentos se dá para a cura de doenças congênitas graves seleção embrionária com finalidade terapêutica.

Para a viabilidade de se constatar tais características, como a cor dos olhos e até mesmo doenças congênitas, ressalta-se a função do Projeto Genoma e das técnicas de engenharia genética, pois o mapeamento dos genes humanos permite a localização de tais atributos, bem como sua alteração.

A complexidade do tema faz emergir diversas questões, dentre as quais a aptidão do Direito para responder às indagações inerentes à reprodução artificial; a possibilidade de uma resposta justa para os dilemas enfrentados; o conceito de uma resposta justa nas hipóteses de reprodução artificial; a suficiência das transformações do ordenamento jurídico para atender às transformações que ocorrem no campo da reprodução assistida e da engenharia genética; etc. (PORTO; FILHO, 2012, p. 76).

Nesse sentido, ressalta-se a importância da Bioética e do Biodireito frente aos problemas que emergem na abordagem da procriação humana assistida, mostrando a importância de se discutir os critérios e limites, a fim de determinar "um liame entre os poderes técnico e ético, o que implica, necessariamente, compromisso em manter a humanização na reprodução humana assistida" (BIANCHINI, 2016, p. 11).

Dessa forma, nota-se que o presente ensaio objetiva discutir as implicações jurídicas e a ressignificações que alguns direitos podem assumir frente à sociedade contemporânea que usufrui, cada vez mais, de técnicas que podem dar uma nova face às futuras gerações, além de mostrar a necessidade uma regulação cuidadosa do tema pelo Estado, tendo em vista a ausência de legislação sobre o assunto no ordenamento pátrio.

\section{REPRODUÇÃO HUMANA ASSISTIDA E PROJETO GENOMA HUMANO}


Os seres vivos, geralmente, tendem a se reproduzir. Há, no entanto, alguns casos em que surgem dificuldades biológicas na reprodução, impossibilitando os pais de gerar filhos por vias naturais.

Tal problemática desencadeou vários desafios à ciência, que passaram desde a identificação das mais variadas causas de infertilidade e seus respectivos tratamentos até o desenvolvimento de métodos que permitissem aos casais inférteis ter filhos. É neste contexto que a reprodução humana assistida ganha espaço e relevância.

As diferentes técnicas que podem ser utilizadas na busca da gestação podem ser divididas em dois tipos: as mais antigas e as modernas: a) as mais antigas, também mais simples, são aquelas em que a fecundação se dá dentro do corpo da mulher, e são conhecidas por inseminação artificial; b) as mais modernas, por sua vez, são aquelas em que a fecundação se dá fora do corpo da mulher, passando pelo procedimento de fertilização "in vitro" (FIV), apresentando diversas variantes.

Além disso, tais técnicas podem ser homólogas, quando os gametas utilizados são do próprio casal que buscam o tratamento, ou heterólogas, quando um ou ambos os gametas são provenientes de indivíduos que não os envolvidos no procedimento.

Deste cenário já decorrem inúmeras problemáticas jurídicas, tais como: a) a busca imediata pelos métodos de reprodução humana assistida, sem antes se tentar diagnosticar os motivos da infertilidade; b) a depreciação da adoção, pois se tem a possibilidade de escolher entre alguém que traria os traços biológicos dos pais e alguém "totalmente estranho"; c) a questão do direito de conhecer a própria origem nos casos de fertilização heterólogas, tendo em vista o direito ao anonimato do doador; etc.

O Projeto Genoma Humano, por sua vez, é o ápice da biologia molecular, que teve início em 1953, quando Francis Crick e James Watson descobriram a estrutura helicoidal do DNA. Diante das novas possibilidades, tornou-se viável o acesso ao interior da estrutura molecular do DNA, bem como a possibilidade de sua modificação, por meio dos conhecimentos da engenharia genética e do conjunto de técnicas e procedimentos de manipulação do genoma dos seres vivos.

Diante disso, o uso de tais métodos pode ter finalidades diversas, o que permite uma subdivisão entre a intervenção genética com fim terapêutico, em que se busca a cura de moléstias genéticas hereditárias; ou sem fins terapêuticos, quando o que se objetiva são finalidades não-curativas, como efeitos estéticos, capacidade intelectual, alteração do sexo, etc. gerando os chamados “designer-babies". 


\section{SELEÇÃO EMBRIONÁRIA E O RISCO DE EUGENIA}

Ao abordar o tema da eugenia, tem-se como precursor a figura de Galton, o qual elaborou diretrizes para o estudo e manipulação de características hereditárias do ser humano, com o fim de aprimorá-las. A partir disso, utilizou a ideia de raça e passou a defender o aprimoramento racial - em especial no diz respeito às capacidades mentais -, com base na ideia de que os indivíduos portadores de deficiências deveriam ser proibidos pelo Estado de se reproduzirem (SANTOS, et al., 2014).

A respeito do tema, passou a existir, a partir do início do século $\mathrm{XX}$, a divisão entre eugenia positiva e eugenia negativa. A primeira foi definida como aquela em que se estimula a boa reprodução em seres humanos, ao passo em que a segunda seria aquela em que se limita a má reprodução. Já no século XXI, a terminologia passa a ser “eugenética negativa", para se referir à prevenção de doenças genéticas e "eugenética positiva", quando o foco é a possibilidade de "melhoramento" de características físicas e mentais do ser humano (SANTOS, et al., 2014).

Nesse sentido, as técnicas de reprodução assistida, ainda que ausentes as possibilidades trazidas pelo emprego da engenharia genética, já podem ser usadas como forma de seleção racial. Assim, por exemplo, é o relato de uma mulher de cor que, na Itália, conseguiu garantir que lhe fosse implantado o óvulo de uma mulher branca, com a finalidade única de ter um filho branco. Tal situação se torna ainda mais preocupante ante a possibilidade de países mais poderosos imporem seus critérios raciais aos demais, tendo em vista o seu poder econômico e também o monopólio das ferramentas biomédicas (BLÁZQUEZ apud SCALQUETTE, 2010, p. 96).

Nesta perspectiva, é importante salientar a existência da Declaração Universal sobre o Genoma Humano e os Direitos Humanos (UNESCO), que, com base no respeito à dignidade humana e aos direitos humanos, estabelece que "o genoma humano constitui a base da unidade fundamental de todos os membros da família humana bem como de sua inerente dignidade e diversidade" e que, "num sentido simbólico, é o patrimônio da humanidade".

Diante desta especial proteção, a mesma declaração assegura, em seu artigo $8^{\circ}$, que "cada indivíduo terá direito, conforme a legislação nacional ou internacional, à justa 
indenização por qualquer dano sofrido resultante, direta ou indiretamente, de intervenção sobre seu genoma.”.

Além disso, a Declaração sobre as Responsabilidades das Gerações Presentes em Relação às Gerações Futuras (UNESCO, 1997), determina, em seu artigo 1º, que "as gerações presentes têm a responsabilidade de garantir que as necessidades e os interesses das gerações presentes e futuras sejam plenamente salvaguardados".

No mesmo sentido, seu artigo $3^{\circ}$ prevê: "as gerações presentes devem esforçarse para assegurar a manutenção e a perpetuação da humanidade, com o devido respeito pela dignidade da pessoa humana. Consequentemente, a natureza e a forma da vida humana nunca devem ser prejudicadas, sob qualquer aspecto".

No âmbito do ordenamento jurídico brasileiro, a Constituição Federal trouxe um rol de direitos fundamentais e sociais, além de eleger a dignidade humana como fundamento da República Federativa do Brasil. Dessa forma, é preciso analisar se as descobertas promovidas na área da reprodução humana assistida e da engenharia genética se mostram em consonância com a tutela desses direitos, além daqueles previstos pelas Declarações acima mencionadas, bem como se representam benefícios para a espécie humana.

Ademais, outro problema colocado ao se enfrentar o assunto diz respeito ao fato de que o emprego de tais técnicas permite que se escolha por outro alguém "que não possui poder decisório, simplesmente por ainda não existir” (BIANCHINI, 2016, p. 114).

Neste cenário, é importante ressaltar que o Código Civil brasileiro, ao tratar de eventuais direitos daqueles que ainda não foram concebidos, fala apenas de questões sucessórias e testamentárias ${ }^{3}$, sem se preocupar com a proteção de outros aspectos, inexistindo uma atenção especial às polêmicas que emergem ante as possibilidades trazidas pela procriação humana assistida. (BIANCHINI, 2016).

Outro ponto salientado por alguns estudiosos diz respeito aos resultados e efeitos que podem surgir. Nessa perspectiva, Bianchini (2016), em consonância com a Declaração sobre as Responsabilidades das Gerações Presentes em Relação às Gerações Futuras, introduz o debate a respeito da responsabilidade da geração atual pelas gerações futuras, a qual abarcaria os já nascidos, os concebidos e até mesmo o que ainda não

\footnotetext{
${ }^{3}$ Art. 1.952. A substituição fideicomissária somente se permite em favor dos não concebidos ao tempo da morte do testador.
} 
foram concebidos, mas o serão. Ou seja, "trata-se de uma linha sucessória da raça humana, ligando uma geração a outra. É a ininterrupta amarração que vincula o passado ao presente e vice-versa, de tal forma que todas as pessoas de todos os tempos estejam vinculadas" (BIANCHINI, 2016, p. 113).

Assim, a partir dessa vinculação, surge a ideia de responsabilidade das ações dos seres humanos de hoje em relação aos seres humanos do futuro, motivo pelo qual as "ações positivas ou não, produzirão efeitos no futuro e devem, cautelosamente, ser pensadas e planejadas". Em outras palavras, "trata-se de uma responsabilidade que vincula as gerações; por isso, importante observar, no que tange à reprodução humana assistida, a relevância do domínio das ações atuais, para que no futuro esse controle possa render frutos desejáveis" (BIANCHINI, 2016, p. 114).

Diante de todas essas considerações é que se ressalta a importância da Bioética e do Biodireito no que diz respeito à integração entre a ética e as ciências relacionadas à vida humana, buscando, assim, traçar os caminhos que ligam os avanços científicos nas áreas médicas com o respeito à vida e à dignidade humana, por meio de uma abordagem interdisciplinar (BIANCHINI, 2016, p. 118).

\subsection{SELEÇÃO TERAPÊUTICA, EUGÉNICA E CRITÉRIOS DE DIFERENCIAÇÃO.}

No cenário acima narrado, a combinação da reprodução humana assistida, do uso do diagnóstico genético pré-implantacional (PGD) e das técnicas de engenharia genética concretiza a possibilidade de exame genético dos embriões e surgem, dessa forma, maiores opções reprodutivas, por meio de ferramentas que permitem, por exemplo, descartar embriões que apresentam algum tipo de anomalia, enfermidade ou predisposição.

Frisa-se que o diagnóstico pré-implantacional consiste na possibilidade de se realizar um exame genético antes da implantação dos embriões, o que permite a escolha daquele que tenha determinadas características. A engenharia genética, por outro lado, diz respeito aos processos que permitem a manipulação do genoma, com a introdução, supressão ou alteração de determinados genes.

Nesse sentido, a primeira vez que as técnicas de diagnóstico pré-implantacional foram utilizadas foi em 1989, com o fim de identificar o sexo e implantar um embrião de 
sexo feminino, evitando, assim, uma doença que se desenvolvia apenas nos homens. Depois, o mesmo procedimento foi utilizado para identificar embriões com fibrose cística e selecionar aquele sem a moléstia. Hoje a técnica é usada para detectar outras doenças genéticas, como beta talassemia, anemia falciforme, hemofilia, etc. Neste cenário, contudo, a mesma tecnologia pode ser empregada para a determinação de características como cor dos olhos, altura, cor da pele, inteligência, sexo, etc.

É diante disto que surge a diferenciação entre a seleção com finalidade terapêutica e as que não possuem tal finalidade. Neste sentido, Juan Luis Iglesias Prada (1995) esclarece que:

(...) em geral os procedimentos de modificação germinal não terapêutica são per se contrários à dignidade humana e, por isso, em nenhum caso devem ser considerados patenteáveis. Seria o caso de modificações fisiológicas hereditárias (mudanças na cor dos olhos, indivíduos mais altos, louros, esbeltos) e em definitivo, a eugenia positiva ou negativa ou de criação e seleção de raças humanas pelo próprio homem, que em alguns supostos poderiam atentar contra o princípio constitucional do livre desenvolvimento da personalidade e, inclusive, nos países mais avançados constituem ilícitos penais.

Nota-se que a intervenção com finalidade terapêutica pode se dar de diferentes modos no âmbito da engenharia genética. Assim, quando o fim for corrigir um gene que apresenta uma falha, ocorrerá o que se chama de modificação genética. Outra hipótese é a substituição, a qual procede à troca de um gene portador de alguma anomalia por outro tido como normal. Por fim, pode ainda ocorrer a inserção genética, em que se coloca um gene normal com o fim de atingir determinado resultado, somando-se outras células a um gene anômalo (DINALTI; TAVARES apud BIANCHINI, 2016, p. 113).

Mesmo nesses casos, contudo, os posicionamentos não são pacíficos, existindo vozes discordantes a respeito da possibilidade do uso de tais técnicas com a dita "finalidade terapêutica", a qual "pode ser vista com maus olhos exatamente pela interferência da seleção natural da espécie humana, já que há uma intromissão na decisão sobre a vida e a morte ou mesmo na existência ou não de algumas doenças" (BIANCHINI, 2016, p. 113).

Um critério que poderia ser levado em conta para distinguir os dois tipos de procedimento diz respeito ao fato de se referir a um genótipo normal ou anormal. Contudo, definir tais parâmetros também engendra problemáticas no que concerne ao 
modo de se distinguir a normalidade/anormalidade daquilo que seria simples variabilidade genética da espécie humana.

Ou seja, um problema que emerge neste cenário é delimitar, a priori, o que se entende por enfermidade, questão que se encontra em um espaço de subjetividade e incertezas, fato que dificulta a identificação de fronteiras entre o terapêutico e o não terapêutico, além de trazer o risco da excessiva ampliação da primeira categoria. $O$ cenário é analisado de forma crítica por Juliana Araújo Lemos da Silva Machado (2009):

E, no campo da engenharia genética, haverá sempre o perigo de que alterações genéticas sejam feitas em prol de uma "melhora" ou "depuração" da composição genética do ser humano, muitas vezes atuando sobre grupos sociais específicos (como negros, índios, portadores de necessidades especiais), ou, ainda, objetivando alterar genes em prol da obtenção de certos caracteres fenotípicos social e culturalmente estabelecidos como "superiores" (pele branca, olhos azuis, alta estatura, etc.), o que certamente constituiria verdade afronta à dignidade da pessoa humana, podendo ainda resvalar para o surgimento de uma nova forma de discriminação social (de fundo genético).

Outro fundamento trazido para diferenciar as situações de uso das técnicas médico-científicas pode ser apreendido nos ensinamentos trazidos por Hartmut Kress (apud SCALQUETTE, 2010), o qual diferencia a necessidade real e a necessidade criada, a qual impõe uma lógica de consumerismo médico e decorre de uma ampliação das ofertas médicas, caracterizando necessidades secundárias, e não necessidades terapêuticas reais. Diante de tal diferenciação é que "deve-se refletir criticamente sobre até que pondo a medicina reprodutiva desperta necessidades artificiais ou excessivas abrindo espaços de liberdade e decisão eticamente questionáveis" (KRESS apud SCALQUETTE, 2010, p. 94).

Neste sentido, ao debater quais características são ou não prejudiciais, Scalquette (2010, p. 97) aponta que tal escolha envolve um juízo valorativo, o qual poderá eleger "critérios discriminatórios e que atendem aos interesses de uma classe dominante, seja pelo poder político, econômico ou social". Além disso, a autora aponta que tal escolha, ao longo da história, além de arbitrária, foi cruel, impondo o "domínio de brancos sobre negros ou indígenas, domínio de arianos sobre judeus, domínio de homens sobre mulheres etc..." (2010, p. 97).

Diante disto, a jurista defende a ideia de "uma vida saudável, o tanto quanto possível" (2010, p. 97) e traz como exemplo o caso do primeiro bebê que foi concebido 
sem o gene responsável pelo desenvolvimento do câncer de mama e de ovário, o qual seria, de fato, uma conquista médico-científica, e não um juízo discriminatório. Assim, conclui "uma coisa é eliminar o gene causador do câncer, outra é buscar características de valor para alcançar um padrão de excelência” (SCALQUETTE, 2010, p. 97).

O que se percebe, assim, é que a nova realidade trazida pelo alcance da reprodução assistida e das técnicas manipulação gênica traz uma série de questões éticas e filosóficas que precisam ser estudadas. Neste sentido, Juliana González (apud SCALQUETTE, 2010, p. 88) ressalta que "o caminho é de ida e de volta, da ciência para a ética e da ética para ciência", ou seja, "os avanços no conhecimento, realizados particularmente pelas ciências da vida, são inevitáveis para a própria filosofia e para a ética", de forma que surgem algumas perguntas, como "se a ética fica questionada, ou pelo contrário, confirmada pelo novo saber científico, biológico, médico e genético".

Ademais, as novas possibilidades científicas não tornam difíceis de imaginar o advento de um novo entendimento sobre o que seria o "direito à vida", bem como a contextualização do princípio constitucional da "dignidade humana" (art. $1^{\circ}$, III, CF). Caso não existam limites e parâmetros éticos à seleção embrionária, não será difícil imaginar, que em algum tempo, pessoas defendam que o direito à vida englobe nascer loiro, de olhos verdes, com resistência à obesidade, com alto Q.I., etc., sob pena de não se garantir a dignidade humana.

Diante disso, insta salientar o questionamento suscitado por Habermas (2010):

Devemos considerar a possibilidade, categorialmente nova, de intervir no genoma humano como um argumento de liberdade, que precisa ser normativamente regulamento, ou como a autopermissão para transformações que dependem de preferências e que não precisam de nenhuma autolimitação?

No ordenamento brasileiro, não existe uma lei em sentido estrito que discipline as técnicas de Reprodução Humana Assistida, porém o Conselho Federal de Medicina (CFM) preocupou-se em regulamentar a matéria. A última resolução editada que aborda o assunto é a Resolução CFM n 2.121/2015, a qual impôs parâmetros éticos e morais aos métodos em questão.

Tal resolução estabelece que as técnicas de reprodução assistida não podem ser empregadas com o fim de "selecionar o sexo (presença ou ausência de cromossomo Y) ou qualquer outra característica biológica do futuro filho, exceto quando se trate de evitar doenças do filho que venha a nascer.". 
Além disso, trouxe a possibilidade do uso do referido procedimento para a "seleção de embriões submetidos ao diagnóstico de alterações genéticas causadoras de doenças", permitindo que, nesses casos, os embriões sejam "doados para pesquisa ou descartados" (CFM, 2015).

No mesmo sentido, o Código de Ética Médica, instituído pela Resolução do Conselho Federal de Medicina $n^{\circ} 1.931$, de 2009, ao trazer normas éticas que devem ser observadas por todos os médicos no exercício de sua profissão, veda que, na reprodução assistida, se crie embriões "com finalidades de escolha de sexo, eugenia ou para originar híbridos ou quimeras". Estipulou também, em seu artigo 16, que é vedado ao médico “intervir sobre o genoma humano com vista à sua modificação, exceto na terapia gênica, excluindo-se qualquer ação em células germinativas que resulte na modificação genética da descendência.”.

Ademais, existe o Projeto de Lei $\mathrm{n}^{\circ} 115$, de 2015, o qual visa estabelecer o Estatuto da Reprodução Humana Assistida, com o fim de regular a aplicação e utilização das técnicas aqui em análise. Neste sentido, o artigo $6^{\circ}$ deste projeto, em seus incisos tratou de estabelecer as práticas que devem ser vedadas, são elas: "fecundar oócitos humanos com qualquer outra finalidade que não a procriação humana"; "criar seres humanos geneticamente modificados"; "criar embriões para investigação de qualquer natureza"; "criar embriões com finalidade de escolha de sexo, eugenia ou para originar híbridos ou quimeras"; "intervir sobre o genoma humano com vista à sua modificação, exceto na terapia gênica, excluindo-se qualquer ação em células germinativas que resulte na modificação genética da descendência”.

Continuando, o parágrafo primeiro do referido artigo traz uma exceção, segundo a qual "a escolha de qualquer característica biológica do futuro filho será excepcionalmente permitida para evitar doenças ligadas ao sexo daquele que virá a nascer".

Em suma, o cenário de desenvolvimento da reprodução humana assistida e também das técnicas de engenharia genética é marcado pela existência de uma série de dilemas éticos e jurídicos que se se relacionam com a vida, sendo que tais problemáticas aumentam à medida que tais métodos se aprimoram e em que a sociedade passa a buscá-los, ante a possibilidade de cura e, até mesmo, de "perfeição".

Dessa forma, tais situações ressaltam a importância de se discutir os limites, os riscos e os possíveis paradigmas que podem emergir neste novo contexto, tendo em 
vista que o uso indiscriminado das técnicas de diagnóstico pré-implantacional podem atingir desde o direito à identidade até à vida, à liberdade, à integridade psicossomática, à dignidade, à igualdade, etc. (PEREIRA apud BARBOZA;BARRETO, 2001).

\section{A INFLUENNCIA DO CONTEXTO SOCIAL E OS "DESIGNERS BABIES"}

Com base nos fortes argumentos contra a engenharia genética e o apelo dos direitos humanos, não é de se estranhar que tantas pessoas vejam essa nova tecnologia como algo imoral. Existe um forte sentimento popular contra a alteração dos processos naturais, especialmente quando se trata da vida humana. Mas como as opiniões mudam em diferentes contextos sociais? Como os futuros pais reagirão se souberem que outras crianças serão projetadas para serem superiores? (CATALANO, 2012) ${ }^{4}$.

Uma pesquisa realizada por Michael Catalano (2012), Conselheiro Geral da "Southern Research Institute", teve por objetivo responder tais questionamentos, analisando como as opiniões das pessoas mudam quando sabem que outras crianças serão modificadas para serem mais espertas, mais altas e mais atléticas. Os resultados deixaram evidente que mesmo que muitas pessoas sejam contra essa tecnologia, elas se tornam mais propensas a usá-la nessa situação. Neste item serão trazidos os dados da pesquisa em comento.

O referido estudo teve por finalidade analisar como as pessoas iriam reagir a diferentes situações para, assim, permitir uma adequada regulação do assunto. Diante disto, o autor mostra a importância de se olhar para as incertezas e prever as possibilidades de pressões sociais futuras, a fim de se certificar de que o governo possa tomar medidas adequadas e manter a situação sob controle.

Contextualizando o cenário e mostrando a necessidade de uma análise cuidadosa, o autor narra o posicionamento daqueles que são favoráveis ao uso da engenharia genética, os quais destacam, em primeiro lugar, o fato de que os cientistas

\footnotetext{
${ }^{4}$ It might seem like an abstract idea to many, but we may soon be capable of selecting the traits of unborn children. There have been numerous ethical approaches to the issue, with potential benefits and harms outlined, but few scholars have really looked into the great potential for its development as a common practice in society. Studies have shown that the public is opposed to the technologies, but it is necessary to consider the possible scenarios that can alter people's opinions. Through my survey of undergraduate students, I plan to fill in the areas that have been overlooked. What if the practice is not regulated and others in society begin to use it? The public may be against it based on moral views, but we must consider the possibility that it may develop regardless. (CATALANO, 2012).
} 
poderiam prevenir doenças, como a doença de Huntington e a síndrome de Down, através das técnicas de manipulação gênica (RESNIK apud CATALANO, 2012).

De acordo com tal visão, o uso da terapia genética para prevenir a doença não é muito diferente do uso de medicamentos e dos procedimentos que visam à cura de determinada enfermidade (POWELL, RUSSELL E BUCHANAN apud CATALANO, 2012). Nesse sentido, Lee Silver, professor em Princeton, afirma que o argumento de que a engenharia genética é contra a natureza humana é ilógico, pois senão curar uma doença também seria contra a natureza humana.

Alguns estudiosos mais radicais chegam a dizer, em oposição àqueles que se preocupam com os direitos daquele que será concebido, que a aquisição de traços para uma criança não nascida é comparável ao pagamento de aulas de piano (POWELL, RUSSELL E BUCHANAN apud CATALANO, 2012).

Além disso, de acordo com esse posicionamento, a seleção dos traços de uma criança pode ser algo bom. Com a capacidade de selecionar características físicas, mentais e até mesmo emocionais, os pais serão capazes de projetar a "família perfeita" que eles imaginam, evitando, assim, decepções e surpresas - os pais podem imaginar o que querem, e podem obtê-lo (RESNIK apud CATALANO, 2012).

Nesta perspectiva, Catalano cita o cientista de Princeton, Joe Tsien, o qual acredita que se o processo torna as pessoas mais inteligentes, com melhor aspecto e mais atlético, deve ser desejado por todos. Segundo Tsien e outros estudiosos, isso não só melhoraria as vidas dos indivíduos, como também geraria avanços sociais em decorrência das melhorias na inteligência e na produtividade. Tudo isso iria aprimorar o patrimônio genético humano para as gerações futuras (RESNIK apud CATALANO, 2012).

Do outro lado, estão aqueles que, para o autor, representam a posição majoritária e que tem como principal argumento a ideia de que a reprodução humana não deve sofrer interferências e que o ser humano não deve "brincar de Deus" (RESNIK apud CATALANO, 2012).

Outro argumento é aquele relacionado ao amor incondicional dos pais pelos filhos, de forma que a compreensão do que é ser um bom pai não diz respeito à possibilidade de melhorar geneticamente um filho, mas sim à possibilidade de melhorar a sua vida, fazendo-os sentir amados, aceitos e desejados (FLETCHER apud CATALANO, 2012). 
Ainda, a partir de uma abordagem ética, alguns estudiosos afirmam que alterar os genes de uma criança antes que ele nasça seria uma violação de direitos e sacrificaria as liberdades, promoveria a concorrência e acentuaria a hierarquia (SPIER apud CATALANO, 2012), além de acarretar a perda do sentido de humanidade. Outro ponto apresentado pelo autor é de que a proliferação de tais técnicas tornaria o ser humano mero produto manufaturado, sem direitos ou dignidade.

Nesse sentido, são apresentadas três questões para se considerar no debate sobre a engenharia genética: a) o direito de um ser humano a ser humano; b) a dignidade de um ser humano, que seria diminuída por deliberada manipulação genética; e c) a preservação da natureza humana.

Além disso, muitos também afirmam que tal cenário gerará uma busca vã da perfeição e causará maior disparidade entre "ricos" e "pobres", entre o "ideal" e o "nãoideal" humanos. Por esse ângulo, aqueles que são ricos o suficiente para pagar por tais técnicas permanecerão no topo da escala social e continuarão a subir, tendo em vista que seus filhos estarão em uma posição de vantagem sobre todos os outros. Os pobres, por outro lado, não serão capazes de suportar as melhorias, de modo que seus filhos permanecerão no fundo da escala social. O fosso social, assim, irá se expandir, e aqueles que não podem pagar sofrerão, ainda mais, com a pobreza e a falta de oportunidades.

Ademais, existe ainda a possibilidade de defeitos e efeitos colaterais. $O$ exemplo utilizado é o do rato que foi projetado para ter uma memória melhor. A alteração, contudo, foi ligada a um gene que também provocou uma sensibilidade muito maior à dor. Assim, o risco de efeitos colaterais imprevisíveis é outro argumento contra o emprego da engenharia genética.

Assim, alguns especialistas, além de discordâncias morais, têm ressaltado os eventuais riscos nas técnicas de aprimoramento genético.

A pesquisa desenvolvida por Catalano, por sua vez, teve como alvo a opinião do senso comum, e não dos especialistas. Assim, no início, o pesquisador procurou descobrir se os entrevistados esperavam que seus filhos tivessem determinadas características.

Os resultados mostraram que $45 \%$ das pessoas esperam ter um bebê de um determinado sexo; $45 \%$ esperam um determinado conjunto de características físicas, 93\% esperam certo nível de inteligência e características mentais, etc. 
A partir da constatação de que grande parte dos entrevistados almeja determinadas características, o foco passou a ser na maneira de se atingi-las, isto é, na admissibilidade, ou não, do uso da engenharia genética para tais fins.

Nos resultados, as características com maior aceitação de modificação foram inteligência, altura, força e capacidade atlética, mas mesmo nesses casos com baixa porcentagem (2,4 e 2,08, respectivamente).

Continuando a experiência e com o fim de verificar a influência dos fatores sociais, o pesquisador inseriu uma situação em que os amigos dos filhos fossem geneticamente modificados e, assim, mais inteligentes, atléticos e com melhor aparência. Ante a esta nova realidade, as perguntas foram repetidas. O que se percebeu é que as mudanças quanto à inteligência e habilidade atlética subiram para $63 \%$ e $69 \%$, respectivamente.

Diante disto, o autor conclui que se algumas pessoas começarem a usar tais técnicas na concepção de seus filhos, sem a regulamentação estatal, outras pessoas até então relutantes podem mudar suas opiniões, acompanhando a tendência, o que geraria um círculo vicioso e aumentaria as taxas de engenharia genética.

\section{CONCLUSÕES}

A análise do tema buscou evidenciar as inúmeras polêmicas que podem emergir, além da ausência de uma regulamentação estrita sobre o tema no Brasil, tendo em vista a dificuldade de se responder aos dilemas éticos inerentes a este cenário.

Apesar da existência de Resoluções do Conselho Federal de Medicina, bem como de Projetos de Lei, como aquele que visa instituir o Estatuto da Reprodução Humana, o que se percebe é a falta de um progresso efetivo a respeito desta regulamentação.

Assim, fica evidente o descompasso entre os avanços científicos no campo da reprodução humana assistida e da engenharia genética e a morosidade da disciplina legal das possibilidades decorrentes do emprego dessas técnicas.

Um dos principais pontos enfrentados neste cenário, e que foi abordado ao longo deste ensaio, diz respeito à possibilidade do uso das mencionadas técnicas para selecionar o sexo, a inteligência e diversas características físicas do bebê a ser gerado. 
O mesmo questionamento se impõe nos casos em que existe uma finalidade terapêutica, tendo em vista a dificuldade de se estabelecer um critério que diferencie, de maneira pacífica, o que é considerado "normal" do que é tido como "patológico".

Ainda neste sentido, é importante considerar as colocações feitas por Swedin (apud CATALANO, 2012), segundo o qual o controle dessas novas tecnologias só pode ser feito quando todas as nações capazes de usar essas tecnologias concordarem em fazêlo, pois, na ausência de um amplo acordo, as tecnologias serão desenvolvidas como uma questão de competição internacional.

No mesmo sentido, são os resultados obtidos pela pesquisa de Catalano (2012), que deixou claro como o contexto social pode influenciar, de forma determinante, a opção das pessoas a respeito do emprego das técnicas de engenharia genética.

Além disso, o mesmo autor chama atenção para o fato de que os denominados “designers babies" não são mais apenas um sonho tecnológico, futurista, mas sim uma realidade que está se desenvolvendo diante de nossos olhos. Assim, conclui ressaltando a importância de uma regulação, tendo em vista que a sociedade pode não ser capaz de prevenir completamente o aprimoramento genético humano, mas pode impedir que ele fique fora de controle.

\section{REFERÊNCIAS BIBLIOGRÁFICAS}

BARBOZA, Heloisa Helena; BARRETO, Vicente de Paulo. Temas de Biodireito e Bioética. Rio de janeiro: Renovar, 2001.

BIANCHINI, G. M., SANTOS, M. C. C. L. A responsabilidade na reprodução humana eugênica: Aspectos éticos e jurídicos. 2016. Tese (Doutorado em Direito) Pontifícia Universidade Católica de São Paulo, São Paulo, 2016. Disponível em: < https://sapientia.pucsp.br/bitstream/handle/19728/2/Giseli\%20Marques\%20Bianchini.p df>. Acesso em: 14 maio 2017.

CASABONA, Carlos Maria; QUEIROZ, Juliane Fernandes. Biotecnologia e suas implicações ético-jurídicas. Belo Horizonte: Del Rey, 2004.

CATALANO, Michael. The Prospecto of Designer Babies: Is it Inevitable? PIT Journal: Cycle 3, 2012. Disponível em: < http://pitjournal.unc.edu/article/prospectdesigner-babies-it-inevitable>. Acesso em: 10 maio 2017.

CLOTET, Joaquim; GOLDIM, José Roberto. Seleção de Sexo e Bioética. Porto Alegre: EDIPUCRS, 2004. 
CONSELHO FEDERAL DE MEDICINA. Resolução CFM No 2.121/2015. Disponível em: <http://www.cremers.org.br/dowload/2121-2015.pdf>. Acesso em: 10 maio 2017.

https://portal.cfm.org.br/images/stories/biblioteca/codigo\%20de\%20etica\%20medica.pd f>. Acesso em: 10 maio 2017.

COSTA, Judith Martins; MOLLER, Letícia Ludwing. Bioética e Responsabilidade. Rio de Janeiro: Forense, 2009.

DINIZ, Maria Helena. O estado atual do Biodireito. 4 ed. São Paulo: Saraiva, 2007.

GAMA, Guilherme Calmon Nogueira da. O biodireito e as relações parentais. Rio de Janeiro: RENOVAR, 2013.

HABERMAS, Jurgen. O Futuro da Natureza Humana: A caminho de uma eugenia liberal?.Tradução de Karina Jannini. 2 ed. São Paulo: WMF Martins Fontes, 2010.

MACHADO, Juliana Araújo Lemos da Silva. Direito, ética e biossegurança. A obrigação do Estado na proteção do genoma humano. São Paulo: UNESP, 2009.

MARCHETTO, Patrícia Borba (et al.). Temas fundamentais de Direito e Bioética. São Paulo: Cultura Acadêmica: Editora UNESP, 2012.

OLIVEIRA, Deborah Ciocci Alvarez de; JR, Edson Borges. Reprodução assistida: até onde podemos chegar? compreendendo a ética e a lei. São Paulo: Gaia, 2000.

RAIMONDO, Monica di. Parto anonimo e diritto a conoscere le proprie origini. Università di Pisa. Disponível em: <https://etd.adm.unipi.it/theses/available/etd03232015-163050/unrestricted/tesi_finale.PDF>. Acesso em: 13 maio 2017.

ROBERTSON, John A. Assisted Reproduction, Choosing Genes, and the Scope of Reproductive Freedom. George Washington Law Review, Washington, vol. 76, ed. 6, p. 1490-1513, 2008. Disponível em:

$<$ http://heinonline.org/HOL/Page?men_tab=srchresults\&handle=hein.journals/gwlr76\&i $\mathrm{d}=15$

$04 \&$ size $=2 \&$ collection $=$ journals $\&$ terms $=$ Assisted $\mid$ of $\% 20$ reproduction|reproduction|hum an|of|

of $\% 20$ assisted $\% 20$ reproduction|Reproduction.\%20assisted\%20reproduction|of\%20hum an\% 2

Oreproduction|assisted\%20reproduction|aspects\%20of|Of|assisted|Assisted\%20Human\% $20 \mathrm{Re}$

production|Reproduction|legal\&termtype $=$ phrase\&set_as_cursor=97>. Acesso em: 12 maio 2017.

SÁ, Maria de Fátima Freire de; TEIXEIRA, Ana Carolina Brochado. Filiação e biotecnologia. Belo Horizonte: Mandamentos, 2005. 
SCALQUETTE, Ana Claudia Silva. Estatuto da reprodução assistida. 2009. Tese (Doutorado em Direito Civil) - Faculdade de Direito, Universidade de São Paulo, São Paulo, 2009. doi:10.11606/T.2.2009.tde-08032010-095921. Acesso em: 2017-05-13.

SGRECCIA, Elio. Manual de Bioética: fundamentos e ética biomédica. São Paulo: Loyola, 2009.

STANZIONE, Maria Gabriella. Identità del figlio e diritto di conoscere le proprie origini. Torino: Giappichelli editore, 2015.

STORROW, Richard F. Travel into the Future of Reproductive Technology. UMKC Law Review, Kansas City, vol. 79, ed. 2, p. 295-308, 2010. Disponível em: < http://academicworks.cuny.edu/cgi/viewcontent.cgi?article $=1101 \&$ context=cl_pubs >. Acesso em: 07 maio 2017. 